libraries are quite obviously seen as part of the general educational process.

Asado, estancia, gaucho, pampa, tango - these were some new words I returned home with from Argentina - evidence that we were treated well, with an abundance of good food and lively entertainment. But even more, I came away feeling the generosity, warmth and joy of our Latin American art librarian colleagues, and most of all their eagerness to learn and to be part of our global network of art librarians.

\author{
Kerstin Assarsson-Rizzi \\ Chair, IFLA Art Libraries Section \\ Cbief Librarian \\ Vitterbetsakademiens bibliotek \\ Riksantikvarieämbetet/National Heritage Board \\ Box 5405 \\ Storgatan 41 \\ SE-114 84 Stockbolm \\ Sweden \\ Email:kaz@raa.se
}

\section{Editor's note}

Members of ARLIS/UK \& Ireland Council are currently exploring ways in which the Section of Art Libraries' twinning concept, outlined above by Kerstin Assarsson-Rizzi, might be taken forward.

This is a wonderful opportunity for art library societies worldwide to maintain the momentum generated at IFLA in Buenos Aires last year, and to find means to develop the contacts with Latin American art librarians that were initiated here.

\title{
Elegant Solutions for Preservation
}

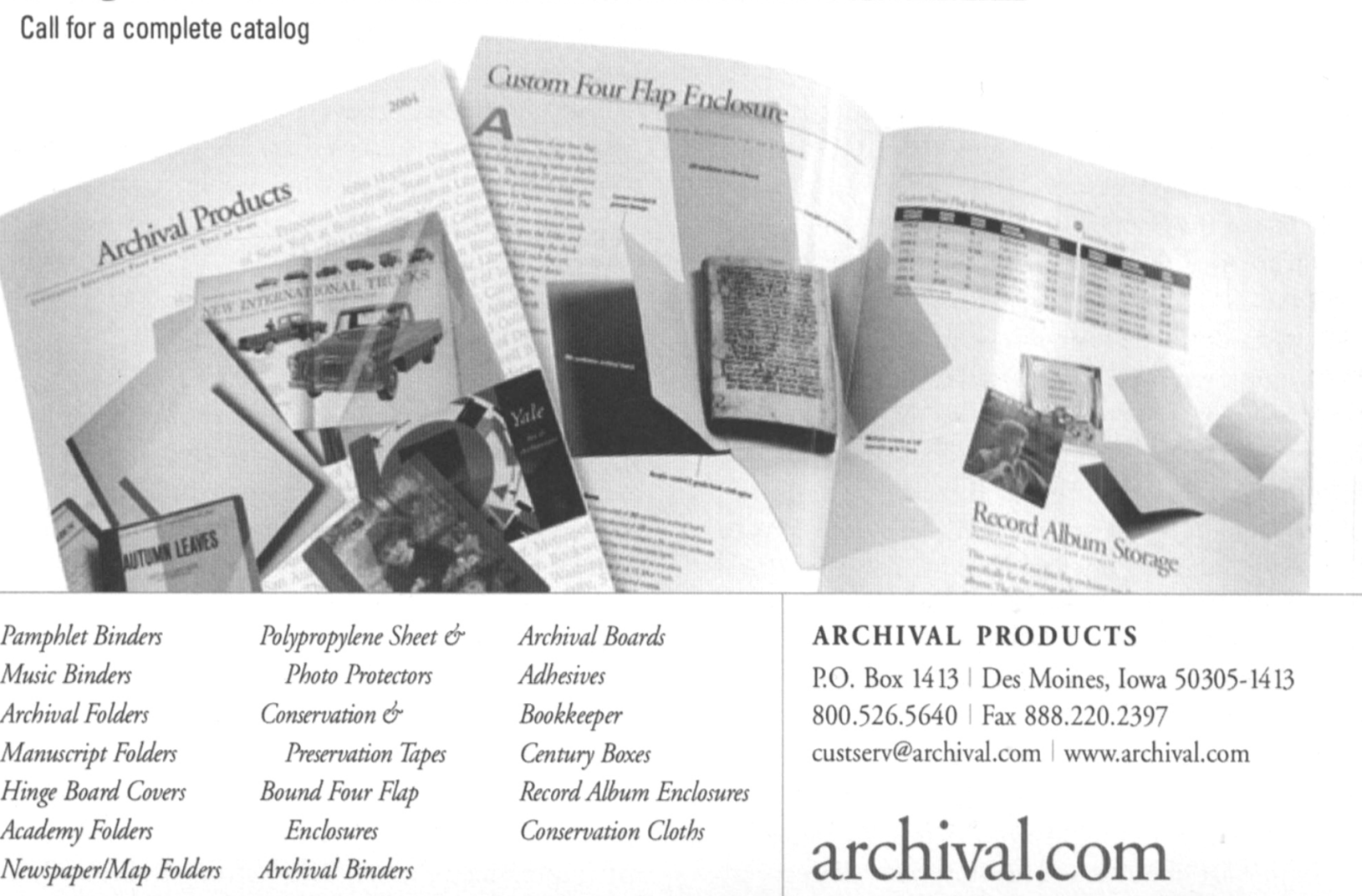

